\title{
FILOSOFIA DA EDUCAÇÃO NO CONTEXTO DE ERASMO DE ROTTERDAM E ROUSSEAU
}

\author{
PHILOSOPHY OF EDUCATION IN THE CONTEXT OF ERASMUS OF ROTTER- \\ DAM AND ROUSSEAU
}

\section{FILOSOFIA DE LA EDUCACIÓN EN EL CONTEXTO DE ERASMO DE ROTTER- DAM Y ROUSSEAU}

\author{
Sidnei Francisco do Nascimento \\ Professor Doutor da Universidade Federal do Maranhão (UFMA). \\ sidneifn@bol.com.br
}

RESUMO: Erasmo e Rousseau concordavam com o cuidado que os pais deveriam ter com a escolha da ama de leite. Criticavam o despotismo dos professores e o método de ensino que não respeitasse a liberdade e a individualidade da criança. Propagavam uma religiosidade sincera e interior sem ritos e formalismos e concebiam como princípio de uma boa educação a formação intelectual e moral baseada em suas concepções sobre a natureza.

PALAVRAS-CHAVE: Erasmo. Rousseau. Religião. Educação. Razão. Natureza.

ABSTRACT: Erasmus and Rousseau agreed in relation to the caution that parents should have when choosing a wet-nurse. They criticized teachers' despotism and teaching methods that did not respect the children's freedom and individuality. They spread an inner and sincere religiosity, without rites and formality and understood as the principle for good education the intellectual and moral formation that was based on their conception on nature.

KEYWORDS: Erasmus. Rousseau. Religion. Education. Reason. Nature.

RESUMEN: Erasmus y Rousseau estuvieron de acuerdo con la atención que los padres deben tener la opción de nodriza. Criticado el despotismo de los profesores y el método de enseñanza que no respeta la libertad y la individualidad del niño. Se propaga una religiosidad sincera e interior sin ritos y formalidades y concebido como un principio de una buena educación la formación intelectual y moral basado en sus puntos de vista sobre la naturaleza.

PALABRAS CLAVE: Erasmus. Rousseau. La religión. La educación. La razón. La naturaleza. 
FILOSOFIA DA EDUCAÇÃo | Sidnei Francisco do Nascimento

\section{1 | INTRODUÇÃO}

O humanista cristão do século XVI Erasmo de Rotterdam, também conhecido como o preceptor da Europa, escreveu dois pequenos tratados de pedagogia que ressaltavam a todo o momento, de maneira enfática, o caráter lúdico do ensino-aprendizagem, como se o aluno estivesse brincando, jogando e aprendendo ao mesmo tempo. Primeiramente proponho uma análise do tratado que o humanista dedicou a crianças de dois ou três anos de idade, embora seu conteúdo pudesse servir ainda para crianças mais velhas, intitulado É necessário dar ainda muito cedo às crianças uma educação liberal, para depois apresentar a proposta curricular contida em seu outro opúsculo intitulado O plano de estudos, dedicado a jovens de 12, 13 a 17 anos de idade.

Utilizaremos o método comparativo para refletir a respeito dos tratados de pedagogia de Erasmo e da extensa obra que Rousseau escreveu a respeito de uma filosofia da educação intitulada Emílio ou da Educação. Apesar de viverem em contextos diferentes, o objetivo desse trabalho será cotejá-los tanto pelo viés da filosofia, quando refletem a respeito da natureza humana racional e livre, quanto pelo prisma da pedagogia, quando desenvolvem um programa de matérias que deverá ser ministrado por um professor sempre disposto e preparado para educar com amor, respeito e responsabilidade.

Ambos refletiram a respeito do cuidado que os pais deveriam ter com a escolha da ama de leite. Observavam que essa fora uma figura muito comum e quase indispensável para as famílias nobres e aristocratas, pois auxiliava a criança não só na fase da amamentação, bem como com sua educação. Os pais não deveriam negligenciar a educação de seus filhos. Erasmo nos dizia que "se não educares teu filho serás o pai de um monstro e não de um homem" (ÉRASME, 1992a, p. 489), e Rousseau era da opinião de que "quem não pode cumprir os deveres de pai não tem direito de tornar-se pai” (ROUSSEAU, 1999, p. 26). Assim, ambos consideravam importante a escolha do preceptor, pois esse deveria exercer sua autoridade com comedimento, e o aluno não deveria obedecê-lo por medo, mas por respeito e amizade. Admitiam um sentido de religiosidade que se opunha aos cânones da Igreja Oficial de Roma quando concordavam que a verdadeira religião deveria ser simples e sincera, isto é, sem ritos e formalismos e com muitas obras de caridade. Proclamavam um ecumenismo religioso, em que "todos respeitassem todas as religiões e que vivessem em paz cada um na sua religião” (ROUSSEAU, 1999, p. 423).

\section{2 | ERASMO E SEUS TRATADOS DE PEDAGOGIA}

Erasmo criticava a maneira como os escolásticos ao final da Idade Média se apropriavam da filosofia conceitual de Aristóteles, se esquecendo do principal, ou seja, de fazer a caridade. Se a reforma da Igreja era inevitável no século XVI, devido às críticas que se seguiam contra os ambientes universitário e religioso fossilizados pela escolástica, depravada, caricatural e moribunda (que os humanistas rejeitavam), as perseguições, os infortúnios e dissabores que Erasmo enfrentou por exigir um novo programa de estudos foram iminentes. $O$ humanista era da opinião que, antes dos sete anos de idade, as crianças deveriam aprender alguma coisa. No entanto, "não se deveria torturá-las com estudos muitos exaustivos, como aqueles ditados que se é obrigado a memorizar até o fim com exercícios indigestos" (ÉRASME, 1992a, p. 508).

O humanista cristão condenava a Idade Média em matéria de conhecimento; primeiro, porque o método pedagógico desenvolvido pelas escolas medievais incentivava a memória motora adquirida pela repetição mecânica verbal e, depois, porque era da opinião de que os escolásticos não favoreciam em nada o conhecimento das Escrituras e da filosofia patrística recorrendo aos 
silogismos de Aristóteles. Considerava, também, "teólogos decadentes os que não recorriam às fontes, porque muitos não sabiam o grego nem perfeitamente o latim e, muito menos, o hebraico" (NASCIMENTO, 2006, p. 21).

Havia uma literatura, muito comum no Renascimento, dedicada à educação intelectual, política e moral dos príncipes. Erasmo dedicou seu pequeno tratado de pedagogia É necessário dar ainda muito cedo às crianças uma educação liberal a seu amigo humanista e preceptor que cuidava da educação de uma criança que sucederia seu pai João III no ducado de Clèves, em fevereiro de 1539. O humanista jamais deixou de lado a retomada dos autores antigos como referencial essencial para elaborar suas teorias. Já nas primeiras linhas desse tratado, Erasmo cita Crisipo, filósofo estoico que escreveu sobre a teoria e a prática da pedagogia e que exerceu uma influência considerável sobre o pensamento pedagógico de Quintiliano e Plutarco. O humanista se referia ao estoico para ressaltar que jamais é muito cedo para ensinar a uma criança o cultivo das belas letras, pois "o preceptor deveria aproveitar a sua juventude livre de toda preocupação e de vícios enquanto sua idade é dócil e maleável, pronta e hábil para todo exercício com a capacidade de guardar com alguma facilidade e extrema tenacidade as impressões recebidas" (ÉRASME, 1992a, p. 477).

Para entender sua filosofia da educação, devemos considerar a importância que o humanista cristão atribuía à noção de natureza. Ressaltarei apenas algumas breves passagens contidas em sua obra para compreender a maneira como estavam conjugadas as concepções de natureza, razão e educação. Erasmo nos dizia que "[...] a natureza nos fez para adquirir os conhecimentos, o ardor que nos conduz para eles não seria prematuro, quando a mãe universal ela própria depositou em nós certas sementes [...]" (ÉRASME, 1992a, p. 483).

Em outra passagem o humanista associava a ideia de natureza à razão dessa maneira:

Certamente, as espécies mudas receberam da Natureza, nossa mãe universal, um grande socorro para a realização de suas funções específicas; mas, visto que a providência divina dotou o homem, o único entre todas as criaturas, de potência de razão, é à instrução que ela reservou o papel mais importante. (ÉRASME, 1992a, p. 483).

Mais adiante ele acrescentava que "[...] a substância e o sumo de toda felicidade humana consistem em uma boa instrução e uma educação conforme a regra" (ÉRASME, 1992a, p. 483). O humanista ainda citava outras referências à razão, tais como: "[...] é a razão que faz o homem" (ÉRASME, 1992a, p. 487). Logo a seguir, em outra passagem: "[...] a natureza nos deu um ser para que se construa a virtude conforme os melhores princípios" (ÉRASME, 1992a, p. 491). O autor prosseguia: "[...] que a natureza seja conduzida pela razão e que esta seja conduzida à perfeição pelo exercício" (ÉRASME, 1992a, p. 498). O humanista retomava e traduzia a máxima de Sêneca "(Quid in homine proprium? Ratio): O que é próprio do homem? Viver conforme a razão" (ÉRASME, 1992a, p. 499).

No que diz respeito ao cuidado que se deve ter com a escolha da ama de leite, o humanista era da opinião de que se deve escolher a melhor e que tenha uma moral irreprochável. Erasmo desenvolveu alguns argumentos a favor de uma boa gestação para o desenvolvimento de uma criança saudável do ponto de vista físico e psicológico. Ele considerava fatores externos como o meio em que a criança fora gerada e de que maneira, isto é, se fora concebida com consciência pelos pais e em que condições. Suas preocupações recaíam na responsabilidade dos pais, se essa criança fora gerada com amor e em que condições presentes ou futuras a sua integridade física e psicológica estaria assegurada. 
Ninguém pode prever nem para si próprio, nem para outro uma natureza determinada, no entanto, segundo o humanista, a solicitude dos parentes pode ter alguma influência. O primeiro cuidado que o homem deve ter é com a escolha de uma boa esposa: esta deve ser bem educada e possuir boa saúde. Em segundo lugar, quanto à procriação da criança, o marido não deve ser um bêbado e nem vitimado de paixões violentas. Erasmo admitia, e considerava um mistério, como as disposições dos pais se comunicavam ao feto. Em terceiro lugar, será a mãe que deverá amamentar seu filho; caso não fosse possível por qualquer motivo, seria necessário que se escolhesse uma ama de leite, saudável, que tivesse um leite puro e morais honestas e ainda que não fosse bêbada, briguenta ou desavergonhada. Em último lugar, que a criança fosse confiada no momento oportuno a um preceptor reconhecido entre muitos (ÉRASME, 1992a, p. 501-502).

Erasmo escreve que o sucesso dos estudos depende das boas disposições recíprocas entre o mestre e o aluno. O primeiro cuidado que o preceptor deverá ter é de se fazer amar e que se estabeleça um respeito mútuo e espontâneo. Com o tempo, a criança, que no início havia começado a amar os estudos pelo amor de seu mestre, amará mais tarde seu mestre pelo amor ao estudo (ÉRASME, 1992a, p. 515). Mas a realidade nem sempre fora esta, pois o humanista vivenciara experiências muito dolorosas dentro das escolas que frequentou, com o intuito de aprender a teologia e as artes liberais ${ }^{1}$. Ele mesmo narra, na primeira pessoa, que conheceu muito de perto a criança e o autor da crueldade. A criança com apenas 12 anos de idade fora obrigada por seu preceptor a colocar na boca uma quantidade de excrementos humanos e a engolir uma boa parte. Depois fora suspensa, nua, por cordas que a amarravam pelos braços, sendo castigada com pancadas de varas até o desfalecimento. Quais foram as consequências desse suplício? A criança em breve contraiu uma doença comprometendo sua razão e sua vida. O carrasco escreve para os pais virem buscá-la o mais rapidamente possível. A justificativa era que "a criança havia contraído um mal físico e que, depois de muito tratamento que a escola havia lhe prestado, mesmo assim, ainda continuava com uma incapacidade de restabelecer seu antigo vigor mental" (ÉRASME, 1992a, p. 523-524).

Esta é apenas uma das inúmeras passagens que o humanista narra e que presenciou no ambiente escolar. Em suma, por essas crueldades, Erasmo considerava a sala de aula como salas de torturas, e o preceptor como carrasco, lunático, epilético, leproso e sifilítico, que se utilizava dessas torturas para esconder sua própria ignorância. Se ele não sabia o que ensinar aos seus alunos, recorria à força para ser respeitado. Depois de todas essas penas infringidas à criança, o preceptor acrescentava que o aluno não havia feito nada para merecer tal suplício, mas que, mesmo assim, era necessário humilhá-lo.

A filosofia possui para Erasmo um sentido muito geral, essencialmente moral, com uma predominância da prática sobre a teoria. Assim, a responsabilidade das ações malvadas recai invariavelmente no próprio agente da ação, conduzido por suas paixões desenfreadas. Nesse sentido, a filosofia cristã nos ensina que a nossa inclinação ao mal tem sua sede em nós mesmos desde Adão, o pai do gênero humano. O humanista prosseguia e ressaltava a responsabilidade individual do cristão sobre as consequências de suas ações, afirmando que é absolutamente certo que o mal procede, na maioria das vezes, de maneiras de viver malsãs e de uma malvada educação, sobretudo numa idade tenra e flexível. A cristologia contida em sua filosofia moral considerava Cristo como o pedagogo por excelência que instruiu, suportou, encorajou seus discípulos com doçura, bondade e caridade. Erasmo sugeria que esses preceitos morais deveriam ser imitados e vivenciados na relação do mestre com seu aluno. Sua filosofia da educação se justificava como

${ }^{1}$ As disciplinas consideradas liberais: a poética, a retórica, a história, o conhecimento da Antiguidade, a aritmética, a geografia, a ética, a política e as ciências naturais. 
resultado das críticas que fazia aos cultos, às relíquias e a toda referência iconoclasta que era elaborada e desenvolvida no interior das Igrejas, quando se esquecia do principal, isto é, de uma relação pessoal, sincera e interior diante de Deus.

Erasmo, novamente, aceita a solicitação de outro amigo humanista, também preceptor, e lhe reservou outro pequeno tratado de pedagogia intitulado O plano de estudos. Diferentemente do tratado anterior, esse texto desenvolve um plano de estudos e um método para estudar dedicado aos jovens com a idade dos 12 aos17 anos. Esse método consistia, de maneira resumida, na leitura comentada (praelectio) dos autores, classificados às vezes conforme a ordem de dificuldade crescente (cada um sendo apropriado à idade do aluno e ao seu degrau de desenvolvimento nos estudos latinos e greco-latinos) e em função das suas qualidades literárias, morais ou filosóficas (ÉRASME, 1992b, p. 437).

No início de seu opúsculo sobre a educação, Erasmo nos diz que, de maneira geral, o conhecimento se apresenta sob dois aspectos: o conhecimento das coisas e das palavras. O humanista de Rotterdam nos sugere que o primeiro tem importância, mas o segundo tem prioridade. É necessário entender que as coisas que designam as palavras nos remetem aos significados, e as palavras devemos entendê-las como significantes. O humanista argumentava que conhecemos as coisas pelos sinais, que são as palavras, pois sem elas necessariamente caminharíamos a errar cegamente, a delirar no julgamento que faríamos a respeito das coisas. E mesmo aqueles que privilegiavam as coisas em detrimento das palavras eram os que mais discutiam sobre as nuances verbais.

O humanista de Rotterdam elaborou uma lista de autores, entre os quais gregos e latinos, que deveriam ser utilizados para o ensino das belas letras.

Entre os gramáticos: Teodoro de Gaza, Constantino Lascaris, Nicolas Peroti, Donato, Varão; para ensinar a retórica: Luciano, Demóstenes, Heródoto, Aristófanes, Homero, Eurípedes, Menandro, Terêncio, Virgílio, Horácio, Cícero, César; para ensinar a filosofia: Platão, Aristóteles, Teofrasto e Plotino; para ensinar a teologia: Orígenes, Crisóstomo, Basílio, Ambrósio e Jerônimo. (ÉRASME, 1992b, p. 443-449).

Em suma, Erasmo sempre fora intransigente nesse ponto: em caso de eventuais dificuldades vivenciadas pelo aluno no processo ensino-aprendizagem, será necessário que o preceptor observe e respeite sua liberdade e individualidade.

\section{3 | ROUSSEAU E A EDUCAÇÃO DE EMÍLIO}

Apenas ressaltarei os mesmos temas contidos nos tratados de pedagogia de Erasmo que também foram desenvolvidos por Rousseau em sua obra Emílio ou da educação. O contexto não é mais aquele dos escolásticos, dedicado às matérias especulativas que o humanista criticava. No contexto do século XVIII, Rousseau se opunha à sociedade opressora resultante de uma decadência moral. Considerava o homem civilizado depravado e alienado. Quanto mais se tornavam civilizados, mais se aproximavam da infelicidade. Em sua opinião, "nem sempre os homens mais cultos ou as sociedades mais desenvolvidas correspondiam a um aperfeiçoamento moral proporcional" (PISSARRA, 2002, p. 40-41). Por esses motivos, o preceptor deveria retardar o tempo que fosse necessário para que seu aluno tivesse contato com as cidades cheias de luxo e ociosas. Com a esperança de encontrar Sofia, Emílio deixa a cidade de Paris: "Adeus Paris, cidade célebre, cidade de barulho, de fumaça e de lama, onde as mulheres já não acreditam na honra, nem os homens na virtude" (ROUSSEAU, 1999, p. 490). Emílio nos diz que não há outra felicidade além de viver 
independente com quem se ama, ganhando todos os dias apetite e saúde com o trabalho: "Ele queria apenas como riqueza um pequeno rancho em algum canto do mundo, ao lado de Sofia e da terra em que produziria seu alimento com seu próprio esforço" (ROUSSEAU, 1999, p. 645).

Rousseau nos lembra que "aquele que vos fala não é nem um douto, nem um filósofo, mas um homem simples, amigo da verdade, sem partido, sem sistema" (ROUSSEAU, 1999, p. 117). A antítese do homem de belas letras desferia críticas à sociedade permeada de preconceitos e vícios. O autor ressaltava a diferença que estabelecia entre os conhecimentos que deveriam ser adquiridos daqueles que deveriam ser rejeitados, porque estes não favoreceriam em nada a manutenção dos princípios fundamentais de toda boa educação. No livro III de Emílio, o autor nos dizia que: "É mais que evidente que as sociedades científicas da Europa não passam de escolas públicas de mentiras, e com toda a certeza há mais erros na Academia de Ciências do que em todo um povo de hurões" (ROUSSEAU, 1999, p. 264). Assim sendo, parece-nos compreensível a sua rejeição às "calúnias manifestadas pela filosofia sempre orgulhosa que nos conduz ao fanatismo" (ROUSSEAU, 1999, p. 428). Da mesma forma, não via com bons olhos "os livros de história que se moldavam aos preconceitos e não aos fatos" (ROUSSEAU, 1999, p. 314), bem como se opunha ao conhecimento especulativo, às difíceis questões metafísicas, aos jornais, às traduções, aos dicionários, em suma, o autor se perguntava qual seria a utilidade de toda essa tagarelice.

No entanto, em outras passagens, quando se refere aos mesmos temas inicialmente criticados negativamente, Rousseau nos sugere que em determinadas situações são indispensáveis para uma boa formação moral e intelectual. Ele nos dizia sobre o cuidado que o preceptor deveria ter para conduzir seu aluno aos progressos da geometria que, por sua vez, o auxiliaria no desenvolvimento de sua inteligência: "Assim que ele consiga distinguir o que é útil do que não é, será importante ter muita cautela e arte para conduzi-lo aos estudos especulativos" (ROUSSEAU, 1999, p. 204). O autor também ressaltava o gosto que a criança deveria ter pela ciência e que deveria aprendê-la e amá-la com método e no momento apropriado, pois somente nessas condições o conhecimento será com certeza um princípio fundamental de toda boa educação (ROUSSEAU, 1999, p. 212). Em outra passagem, o autor nos sugeria que a mesma filosofia que calunia o gênero humano é aquela que transforma o selvagem em filósofo:

É preciso que ele (Emílio) trabalhe como um camponês e pense como um filósofo, para não ser tão vagabundo como um selvagem. O grande segredo da educação é fazer com que os exercícios do corpo e os do espírito sirvam sempre de descanso uns para os outros. (ROUSSEAU, 1999, p. 261).

A respeito da noção de natureza e educação Rousseau nos propõe algumas máximas que permeiam sua filosofia da educação, diluídas nas orientações que o preceptor fazia a Emílio, como, por exemplo: "Tudo que atrapalha e constrange a natureza é de mau gosto" (ROUSSEAU, 1999, p. 516). Em outra passagem: "O essencial é sermos o que a natureza nos fez" (ROUSSEAU, 1999, p. 536). Ainda sobre a natureza o autor acrescenta: "Tudo o que não é natural é contra a natureza" (ROUSSEAU, 1999, p. 567). O autor prossegue: "Foi assim que a natureza, que tudo faz do melhor modo, inicialmente o instituiu. Ela lhe dá de imediato apenas os desejos necessários à sua conservação e as faculdades suficientes para satisfazê-los" (ROUSSEAU, 1999, p. 70).

No livro I o autor conjuga a educação da natureza com a educação dos homens e das coisas consideradas como fundamentais, das quais os homens dependem e nelas são formados. A educação da natureza será importante para o desenvolvimento interno de nossas faculdades e de nossos órgãos. A educação dos homens será indispensável para aprendermos a maneira como devemos lidar com nossas necessidades internas, e, por fim, a educação das coisas nos ensinará como adquirir nossa própria experiência sobre os objetos que nos afetam. Rousseau 
acrescentava ainda que, dessas três educações, a da natureza não depende de nós; a das coisas, só em alguns aspectos; a dos homens é a única de que somos realmente senhores (ROUSSEAU, 1999, p. 09).

No entanto, o autor faz uma ressalva no que se refere à educação dos homens, argumentando que se esta não dependesse de nós, seria porque não teríamos a certeza se aqueles que nos circundarão estariam comprometidos com os princípios de uma boa educação. Assim, para conjugar essas fases da educação e revertê-las em nosso proveito, seria necessário que se tivessem bons educadores que circundassem a criança desde seu nascimento para que lhe concedesse 0 sentimento de sua própria existência. Rousseau nos diz que:

\begin{abstract}
Viver não é só respirar, mas agir; é fazer uso de nossos órgãos, de nossos sentidos, de nossas faculdades, de todas as partes de nós mesmos que nos dão o sentimento de nossa existência. O que mais viveu não é o que contou maior número de anos, mas aquele que mais sentiu a vida. (ROUSSEAU, 1999, p. 15).
\end{abstract}

Em outra passagem Rousseau afirma que "existir é sentir" (ROUSSEAU, 1999, p. 392). Essa trajetória deve vir acompanhada por educadores responsáveis, comprometidos com o futuro da criança ao zelar pela sua conservação e saúde. Antes do preceptor será a ama de leite que cuidará da criança. Esta deve ser sadia de coração e de corpo, pois as intempéries das paixões assim como os humores poderiam alterar seu leite. Rousseau argumentava que "se devia ter cuidado com as escolhas dos criados porque poderiam ser irritadiços e se impacientarem, sendo assim, cem vezes mais perigosos para a criança do que os danos do ar e das estações" (ROUSSEAU, 1999, p. 52). Passando essa fase da amamentação, será o preceptor que educará a criança com método apropriado e com dedicação até chegar à vida adulta. O bom método de ensino se traduzirá nessa máxima: "Sempre bastante e nunca demais" (ROUSSEAU, 1999, p. 61).

O bom método deverá ser apropriado à idade da criança e corresponder as suas diferentes fases: na primeira fase, a criança aprende a falar, a comer e a andar aproximadamente ao mesmo tempo. Em sua segunda fase, suas necessidades serão outras, pois, com o desenvolvimento de suas forças, precisará menos dos outros, o que lhe proporcionará os desejos necessários à sua conservação e as faculdades suficientes para satisfazê-las. "Até esse momento ela só se reconhece como um ser físico ocupado com as primeiras operações dos sentidos e que só concebe o que toca" (ROUSSEAU, 1999, p. 342). Segue-se a idade da razão. Nesta fase, o preceptor deverá mantê-la distante das opiniões, dos preconceitos e da impetuosidade das paixões. Essa preocupação do mestre deverá auxiliá-la na relação que manterá com os outros e com o mundo. Eis aí as primeiras sementes de humanidade e de religião. A primeira passagem para a vida moral será vivenciada por Emílio no momento em que sentir que não foi feito para viver sozinho. O sentido de religiosidade, por sua vez, aparecerá quando ele olha para fora de si próprio e contempla a natureza universal que o cerca. Observa que "o mundo é organizado de tal maneira que possui vontade e inteligência, e o ser supremo que ordena todas as coisas o nomeará como Deus" (ROUSSEAU, 1999, p. 285). O vigário diz a Emílio que os verdadeiros deveres da religião são independentes das instituições dos homens. Eis a religião natural como profissão de fé do vigário saboiano apresentado a Emílio.

Chega a idade da sabedoria, e Emílio deverá aprender a lidar primeiro com a perda e depois aprenderá a viver em sociedade. Em última instância, o que se deseja é que Emílio encontre a felicidade: "É preciso ser feliz, caro Emílio, tal é o fim de todo ser sensível" (ROUSSEAU, 1999, p. 623). Mas, como não há felicidade sem coragem e virtude sem luta, Emílio deverá controlar suas afeições e seguir a sua razão e consciência. Uma das maiores provas de amadurecimento é quando o preceptor o aconselha a se separar de Sofia justamente no momento em que Emílio está 
perdidamente apaixonado. Essa difícil decisão o faz refletir a respeito da vida e da morte. Ele reconhece que, cedo ou tarde, tudo o que amamos nos deixará, mas, mesmo assim, nos ligamos a tudo que amamos como se fosse durar eternamente. Emílio, que aprendeu a suportar as dores do corpo, os males físicos, agora deve aprender a suportar as dores da alma. O preceptor orienta-o a aprender a perder o que lhe pode ser tirado, e assim perceberá que o homem a que tudo escapa só goza do que sabe perder. Mas que dura lição é aceitar que o amadurecimento vem acompanhado de sentimentos de perda. A consciência que se tem da transitoriedade da existência humana, do sofrimento do outro, da piedade, da compaixão tornará o sábio mais moderado, contemplando a miséria humana. "A consciência do que foi feito para se perder um dia é que nos tornará mais corajosos na adversidade, e mais constantes em nossos deveres" (ROUSSEAU, 1999, p. 629).

Emílio se separou de Sofia, mas, depois de alguns anos viajando, voltou a encontrá-la e se casou. Agora ele pensa em sua família, em sua casa, em sua terra e viver de seu trabalho. Mas ele sabe que não está sozinho no mundo, e o preceptor não lhe dá descanso com tantos questionamentos a respeito de um projeto que lhe parecera muito simples naquele momento, isto é, de viver feliz com Sofia em algum lugar do mundo. Antes de deixá-lo, o preceptor quer que fique versado em todas as matérias do governo. Para isso deverá responder a essas perguntas: em que momento poderá dizer a si mesmo que a terra é sua? Onde se pode viver sem temer a ninguém? Onde encontrar a paz? Como encontrará a segurança contra os impostos desmedidos? Assim, a reflexão incide na consecução de um contrato social como base de toda sociedade civil em que o direito de todos e de cada um estarão preservados. Agora sim, o preceptor tem certeza de que seu aluno recebeu uma educação completa. Emílio foi um homem bem educado, que saberá tirar proveito do seu trabalho, julgar com equidade e viver em sociedade.

\section{4 | CONSIDERAÇÕES FINAIS}

Erasmo se debatia com o modelo de educação desenvolvido pela escolástica ao final da Idade Média. Recomendava uma educação liberal baseada nas obras dos autores antigos, principalmente os escritos dos gregos e dos latinos. Seu plano de ensino caminhava em direção contrária ao que se ensinava dentro das escolas medievais. Incompreendido pela ortodoxia e pelos reformados, o humanista cristão procurava renovar a interpretação das Sagradas Escrituras, distante do rigor formal incentivado pela lógica de Aristóteles e, ao mesmo tempo, contrária à exegese propagada por Lutero e os luteranos. A teologia, a educação e a filosofia deveriam ser conjugadas com liberdade. Assim, a criança deveria ser educada com o respeito e o cuidado conjugados às suas potencialidades.

Rousseau, por sua vez, se opunha à educação que destilasse preconceitos. Ao observar a vida nas cidades, criticava, ao mesmo tempo, uma educação cheia de etiquetas sociais. A educação deveria ser desenvolvida fora da sala de aula, numa atmosfera campestre. A criança campesina era mais feliz do que a nascida e educada nas grandes cidades. Para Rousseau o amadurecimento passava invariavelmente pela consideração do outro. Era nesse momento que o autor migrava das considerações morais para a vida política. O indivíduo deixa de ser criança quando começa a sofrer pelo sofrimento do outro, quando percebe que não está mais sozinho no mundo e que sua felicidade não reside mais na satisfação apenas de suas próprias necessidades. A noção de cidadania se constrói pelo reconhecimento do outro e pela consciência de que devemos ao mesmo tempo respeitar e conviver com as diferenças. Mesmo envolvidos e reagindo a contextos diferentes, ambos concordavam em muitos aspectos, sobretudo naquele que nos sugere que a boa educação é essencial para nos tornarmos homens melhores e livres, com dignidade e responsabilidade. 
FILOSOFIA DA EDUCAÇÃo | Sidnei Francisco do Nascimento

\section{Referências}

ÉRASME. II faut donner très tôt aux enfants une éducation libérale. Tradução Jean-Claude Margolin. Paris: Robert Laffont, 1992a.

. Le plan des études. Tradução Jean Claude Margolin. Paris: Robert Laffont, 1992b.

NASCIMENTO, S. F. do. Erasmo e Lutero: distintas concepções de livre-arbitrio. 2006. Tese (Doutorado em Filosofia)- Pontifícia Universidade Católica de São Paulo, São Paulo, 2006.
PISSARRA, M. C. P. Rousseau: a política como exercício pedagógico. São Paulo: Moderna, 2002.

ROUSSEAU, J.-J. Emílio ou Da Educação. Tradução Roberto Leal Ferreira. São Paulo: Martins Fontes, 1999. 